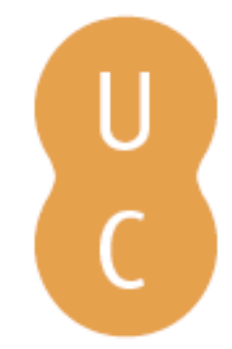

\title{
pommalina
}

\section{Ambiente térmico de sala de aula pode condicionar o desenvolvimento de competências e avaliação de alunos}

\author{
Autor(es): $\quad$ Talaia, Mário; Silva, Marta \\ Publicado por: Imprensa da Universidade de Coimbra; RISCOS - Associação \\ URL \\ persistente: URI:http://hdl.handle.net/10316.2/34878 \\ DOI: $\quad$ DOI:http://dx.doi.org/10.14195/978-989-96253-3-4_77 \\ Accessed : $\quad$ 26-Apr-2023 15:54:50
}

A navegação consulta e descarregamento dos títulos inseridos nas Bibliotecas Digitais UC Digitalis, UC Pombalina e UC Impactum, pressupõem a aceitação plena e sem reservas dos Termos e Condições de Uso destas Bibliotecas Digitais, disponíveis em https://digitalis.uc.pt/pt-pt/termos.

Conforme exposto nos referidos Termos e Condições de Uso, o descarregamento de títulos de acesso restrito requer uma licença válida de autorização devendo o utilizador aceder ao(s) documento(s) a partir de um endereço de IP da instituição detentora da supramencionada licença.

Ao utilizador é apenas permitido o descarregamento para uso pessoal, pelo que o emprego do(s) título(s) descarregado(s) para outro fim, designadamente comercial, carece de autorização do respetivo autor ou editor da obra.

Na medida em que todas as obras da UC Digitalis se encontram protegidas pelo Código do Direito de Autor e Direitos Conexos e demais legislação aplicável, toda a cópia, parcial ou total, deste documento, nos casos em que é legalmente admitida, deverá conter ou fazer-se acompanhar por este aviso.

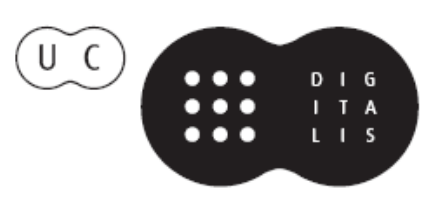



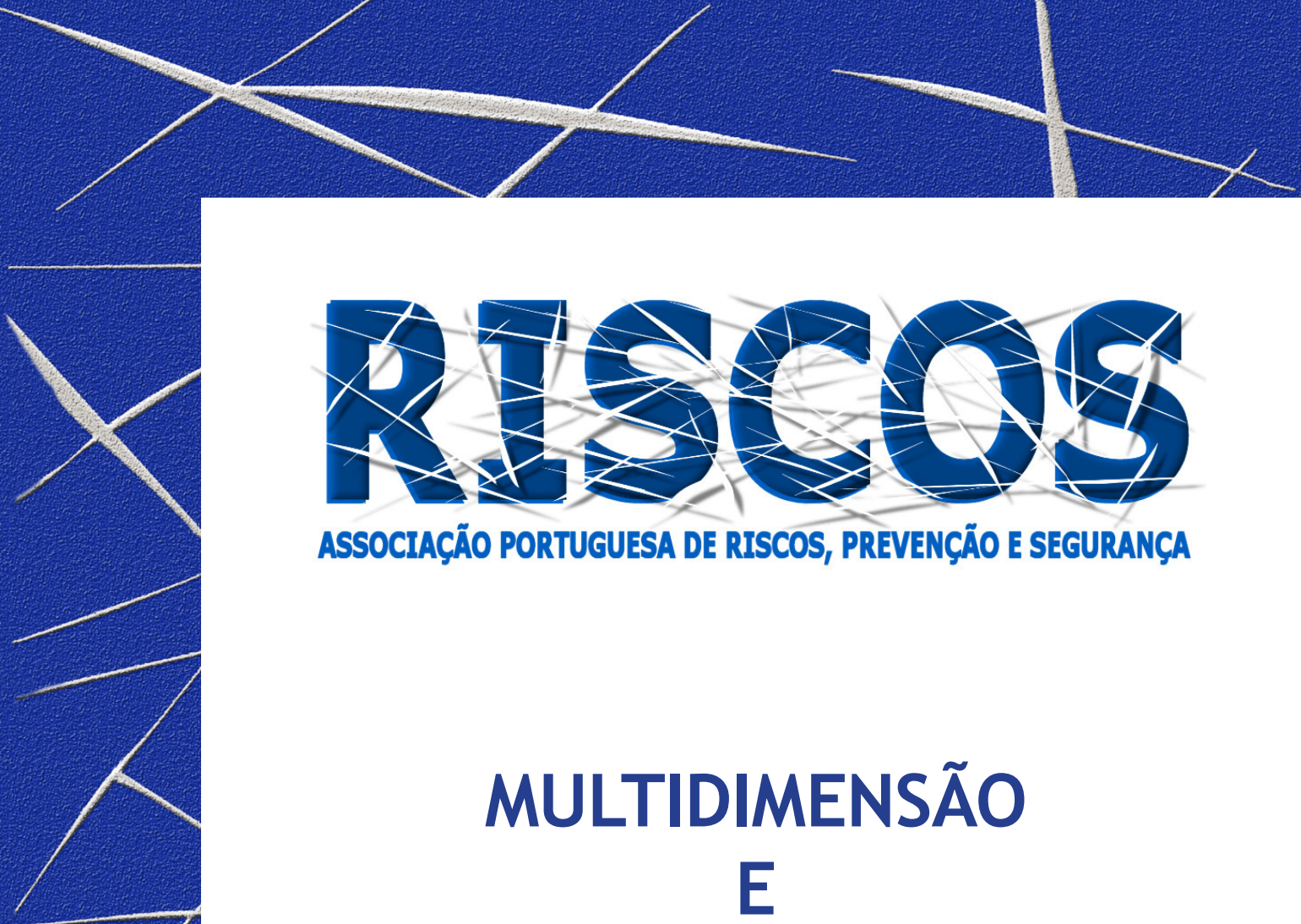

ASSOCIAÇÃO PORTUGUESA DE RISCOS, PREVENCCÃO E SEGURANÇA

MULTIDIMENSÃO

E
TERRITÓRIOS DE RISCO

III Congresso Internacional

I Simpósio Ibero-Americano

VIII Encontro Nacional de Riscos

Guimarães

2014 


\title{
AMBIENTE TÉRMICO DE SALA DE AULA PODE CONDICIONAR O DESENVOLVIMENTO DE COMPETÊNCIAS E AVALIAÇÃO DE ALUNOS
}

\author{
Mário Talaia \\ Departamento de Física, CIDTFF, Universidade de Aveiro \\ mart@ua.pt \\ Marta Silva \\ Departamento de Educação, Universidade de Aveiro \\ martaacsilva@hotmail.com
}

\begin{abstract}
RESUMO
Estudos mostram que o ambiente térmico pode influenciar o ensino e aprendizagem diminuindo os resultados de avaliação. Neste trabalho são usados índices térmicos e uma escala de cores de sensação térmica, onde os alunos aquando da realização de questões problema no final de aulas selecionavam a sua zona de conforto/ desconforto. Os resultados obtidos mostram que o desenvolvimento de competências e a avaliação registada são condicionados pela performance do ambiente térmico. Para o verão e quando a sensação térmica está na zona de conforto os resultados obtidos, em termos de avaliação, são positivos. Quando os valores da sensação térmica divergem da zona de conforto registam-se resultados negativos, abaixo de $50 \%$ numa escala de $0 \%$ a 100\%. A análise dos resultados obtidos mostra, ainda, que este método é uma ferramenta importante para avaliar o risco quando as condições térmicas do interior de uma sala de aula divergem da zona de conforto, afectando o processo de ensino e aprendizagem.
\end{abstract}

Palavras-chave: Ensino e aprendizagem, sensação térmica, avaliação e índices térmicos.

\section{Introdução}

No processo de implementação do Desenvolvimento Sustentável a Educação é, de facto, a principal ferramenta que se dispõe para atingir o paradigma do Desenvolvimento Sustentável. A UNESCO ao instituir a Década das Nações Unidas da Educação para o Desenvolvimento Sustentável (2005-2015) revelou preocupações com o desenvolvimento e pretendeu, deste modo, melhorar a qualidade do ensino, facilitar a troca de experiências entre os diversos atores envolvidos e fazer com que haja uma maior atenção pública relativa a este assunto.

Ergonomia sendo um conjunto de disciplinas permite estudar a organização do trabalho no qual existe interações entre seres humanos e os sistemas que os envolvem. 0 principal objetivo da ergonomia é desenvolver e aplicar técnicas de adaptação do ser humano visando a otimização do seu bem-estar. Com o desenvolvimento de pesquisas em torno da Ergonomia surgiu a necessidade de avaliar o efeito do "clima" no local de trabalho e no ser humano. 0 estudo do conforto térmico tem uma forte importância económica.

Atualmente, quando se fala do desenvolvimento cognitivo e dos processos de aprendizagem de alunos devem-se considerar aspetos importantes relacionados com a motivação, os estímulos do meio (ambiente envolvente da pessoa), as relações sociais e a educação recebida, entre outros (Coll et al., 1995).

O surgimento de novos ambientes de ensino e a inclusão quase que obrigatória da informática na escola, traz um novo fator que diretamente pode interferir no desempenho, na motivação e na aprendizagem dos alunos, o conforto ambiental (Lula et al., 2002).

É sabido que a preocupação com o desempenho térmico nas escolas públicas tem tido pouca importância. Muitas edificações escolares públicas não satisfazem as necessidades básicas de 
conforto. Certamente estas condições interferem negativamente na motivação e concentração dos alunos. Desta forma, é necessário que numa arquitetura escolar se tenha em conta as necessidades de conforto térmico, de forma a proporcionar um ambiente agradável e que favoreça o ensino e aprendizagem (Nogueira \& Nogueira, 2003). Wyon (2010) relacionou o conforto térmico com o ensino e aprendizagem de alunos e apresentou dados registados em salas de aula de duas escolas na Dinamarca, envolvendo cerca de 300 alunos, que mostram uma diminuição dos resultados de avaliação de $3,5 \%$ dos alunos por cada ${ }^{\circ} \mathrm{C}$ de aumento de temperatura interior da sala de aula.

\section{Métodos}

O estudo, realizado em sala de aula, utilizou a metodologia de investigação-ação, de carácter empírico, recorrendo a uma metodologia mista, onde foram utilizados métodos quantitativos e métodos qualitativos de recolha de dados.

Ao longo da implementação em sala de aula, foram propostas aos alunos diferentes atividades, com a utilização de fichas de trabalho/questões-aula. Estas questões-aula tiveram como objetivo avaliar os conteúdos lecionados na aula, e eram aplicadas sempre que se considerava oportuno. Os alunos não tinham conhecimento prévio da sua realização. Nas questões-aula era apresentada uma escala de cores onde os alunos selecionavam a cor correspondente à sua sensação de conforto térmico que sentiam aquando da realização da atividade.

Os parâmetros termohigrométricos foram registados usando um psicrómetro construído pelos alunos. Foi analisada a influência da temperatura e da humidade relativa do ar em diferentes índices térmicos. $O$ estudo foi realizado durante o verão e para avaliar a sensação de conforto foi usado o índice EsConTer (Talaia \& Simões, 2009).

\section{Resultados e Discussão}

A Figura 1 mostra como o índice temperatura e humidade ITH, o índice EsConTer e o índice de calor IC variam com a temperatura interior da sala.

A observação do gráfico da Figura 1 mostra que há uma excelente correlação nos valores obtidos para o índice ITH, índice de Calor IC e índice EsConTer (Sensação Térmica), quando a temperatura
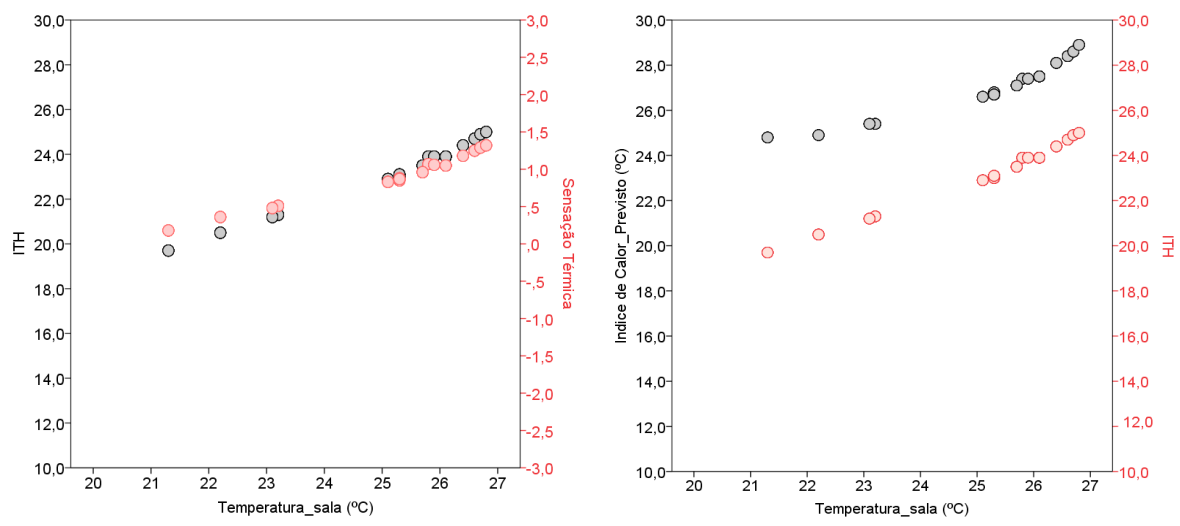

Figura 1 - ITH, Sensação Térmica e Índice de Calor "versus" temperatura do ar. 
Neste estudo é apresentado um grupo de alunos, que tiveram aulas em turno, e são designados por Ai com i=10 a 17.

A Figura 2 mostra como a sensação térmica condiciona a avaliação dos alunos.

Os gráficos da Figura 2 apresentam como ordenada (lado esquerdo) a Avaliação_j com j=1 a 5 indicada por colunas, como ordenada (lado direito) a Sensação Térmica real indicada pela linha quebrada e a linha horizontal a Sensação Térmica prevista.
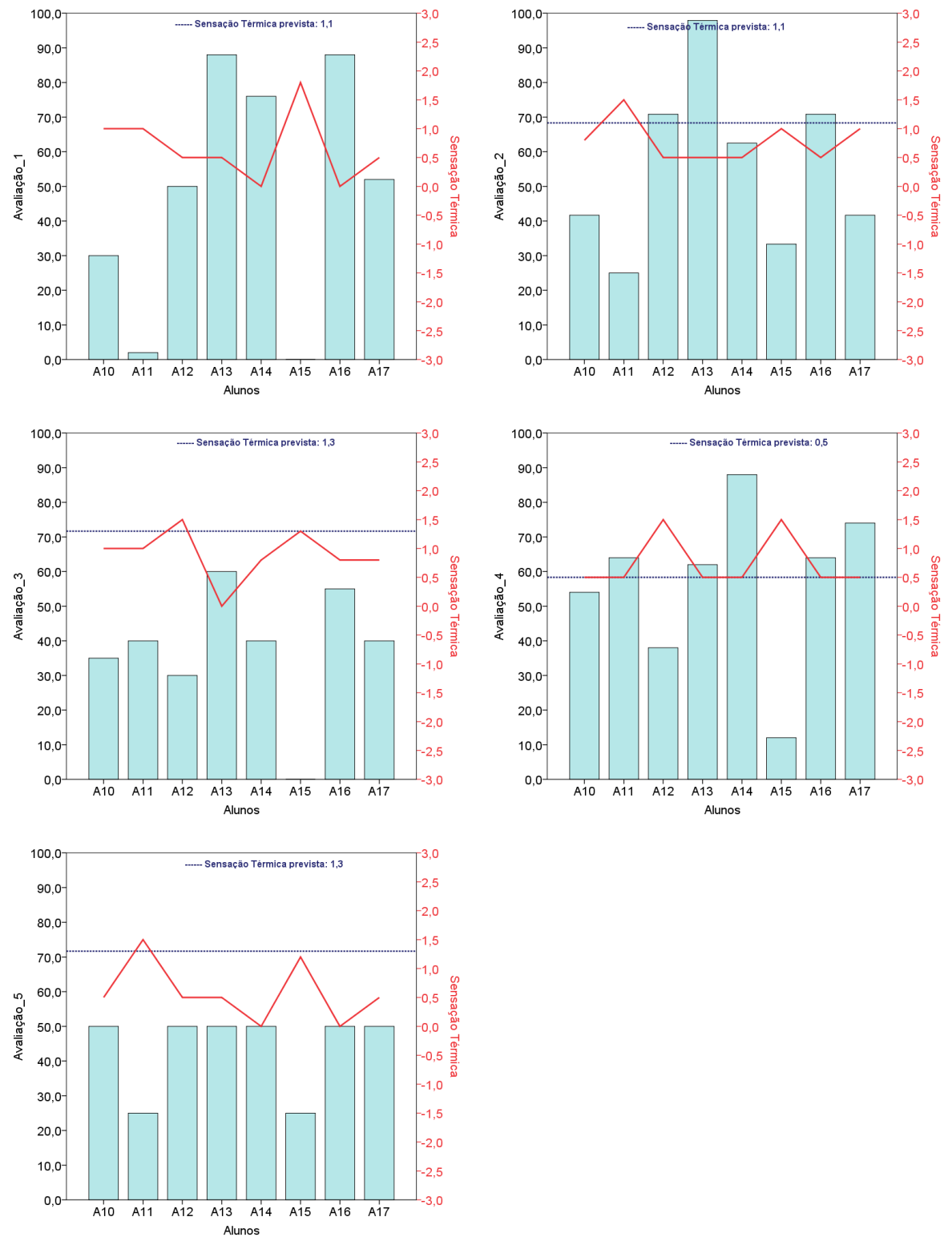

Figura 2 - Avaliação e Sensação Térmica, por aluno 
A Figura 3 mostra os resultados para alguns alunos, em termos de Avaliação_j.
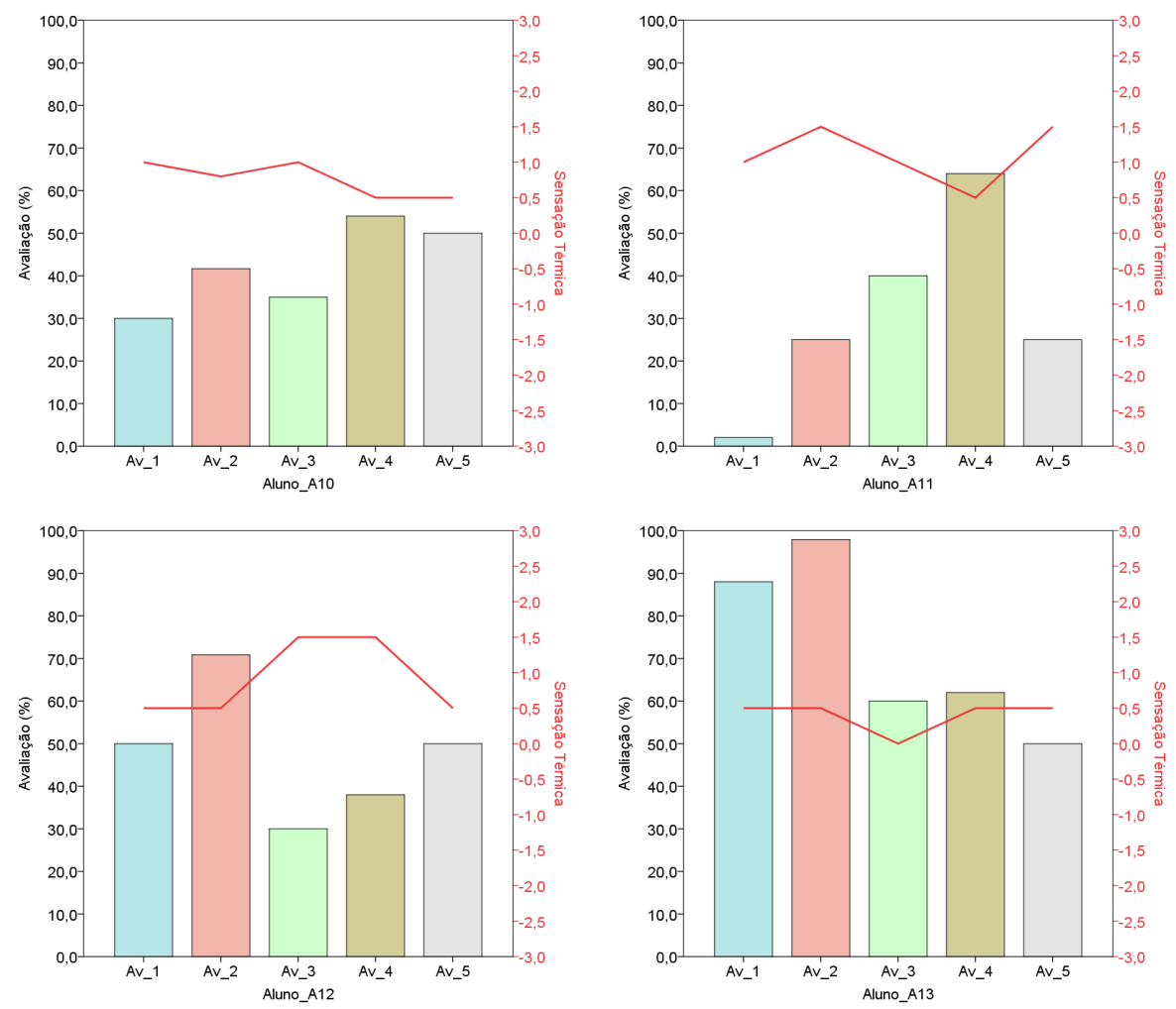

Figura 3 - Sensação térmica versus avaliação do Aluno_A10 ao A13 (exemplos).

A observação dos gráficos da Figura 3 mostra para cada Avaliação_j, os resultados obtidos pelos alunos e de que modo são influenciados pela sensação térmica sentida. Na prática, como seria esperado, quando a sensação térmica se situa na gama de conforto térmico, os resultados são positivos. Quando a sensação térmica sentida pelo aluno suscita um ambiente ligeiramente quente $(+1.0)$ a quente $(+2.0)$ os resultados, no geral, tendem para valores negativos. Os valores da sensação térmica sentidos pelos alunos estão muito próximos da sensação térmica prevista quando se aplica o índice EsConTer. Quando se avalia para o valor previsto da sensação térmica o número de insatisfeitos, índice $P P D$, os resultados mostram que para a Avaliação_1 e Avaliação_2 pode registar cerca de 30\% de insatisfeitos, para a Avaliação_3 e Avaliação_5 cerca de $40 \%$ de insatisfeitos e para a Avaliação_4 cerca de 10\%. Nestas circunstâncias os resultados obtidos mostram inequivocamente que o ambiente térmico de uma sala de aula condiciona o desenvolvimento de competências e a aprendizagem.

\section{Conclusão}

A avaliação dos alunos mostrou que os resultados obtidos são influenciados pelo ambiente térmico da sala de aula. 
Os resultados obtidos permitiram conhecer um patamar de risco que as sensações térmicas sentidas pelos alunos pode condicionar o desenvolvimento de competências e a aprendizagem. Estudos desta natureza parecem ser oportunos quando hoje se vive a problemática do aquecimento global e se debate a problemática energética na vertente da melhoria do bemestar, fadiga e índices de produtividade intelectual.

\section{Agradecimentos}

Um autor agradece o financiamento de subsídio, para este trabalho, realizado pela FCT/MEC através de fundos nacionais (PIDDAC) e cofinanciado pelo FEDER através do COMPETE - Programa Operacional Fatores de Competitividade no âmbito do projeto PEst-C/CED/UI0194/2013.

\section{Bibliografia}

Coll, C., Palácios, J. \& Marchesi, A. (1995). Desenvolvimento psicológico e educação: psicologia evolutiva. Porto Alegre: Artes Médicas.

Lula, C.C.M., Silva, L.B. (2002). O Conforto ambiental e a Motivação: Implicações no Desempenho de Alunos em Ambientes Climatizados. ABERGO, Recife, ANAIS

Nogueira, M.C.J.A. \& Nogueira, J.S. (2003). Educação, meio ambiente e conforto térmico: caminhos que se cruzam. Revista Electrónica em Educação Ambiental, 10, 104-108

Talaia, M. \& Simões, H. (2009). Índices PMV e PPD na Definição da "performance" de um Ambiente. In Livro de atas do V Encontro Nacional de Riscos e I Congresso Internacional de Riscos. Coimbra, Portugal.

Wyon, D. (2010). Thermal and air quality effects on the performance of schoolwork by children. http:// web1.swegon.com/upload/airacademy/seminars/documentation_2010. 